\title{
EDITORIAL
}

Adv Clin Exp Med 2014, 23, 4, 497-504

(c) Copyright by Wroclaw Medical University ISSN 1899-5276

AgnieszKa Kosmowska-Miśków

\section{The Role of Vitamin D3 in Inflammatory Bowel Diseases}

$2^{\text {nd }}$ Department and Clinic of Pediatrics, Gastroenterology and Nutrition of the Wroclaw Medical University, Poland

\begin{abstract}
Vitamin D3, combined with its nuclear receptor, regulates more than 900 genes, which is the reason why its effect is pleiotropic. Among other effects, it influences the immunological system. Its deficit may be one of the environmental factors taking part in the development of auto-immunological diseases. The studies reveal that, among others things, inflammatory bowel diseases occur in higher latitudes, with lower exposure to solar radiation and with decreased production of vitamin D3 in the skin. Patients with inflammatory bowel disease have vitamin D3 deficiency more frequently. The application of vitamin D3, especially among adults with inflammatory bowel diseases, positively influences bone turnover markers and mostly due to its influence on immunological processes, vitamin D3 may be useful in the treatment of the primary health condition. It is necessary to determine the dosage range, as well as the optimal level of vitamin D3 metabolite-25OHD3, where the immunosuppressant effect is the best, with no toxic effects. Studies of vitamin D3 analogues deprived of the hypercalcemic influence, but with other merits of the basic substance remaining intact, are particularly promising (Adv Clin Exp Med 2014, 23, 4, 497-504).
\end{abstract}

Key words: vitamin D3, inflammatory bowel disease.

The basic function of vitamin D3 in the body is its influence on keeping the homeostasis of calcium metabolism, preventing the appearance of rickets, osteomalacia and osteoporosis $[1,2]$. Vitamin D comes from food - ergocalciferol (vitamin D2), and mostly it is synthesized in the skin under the influence of ultraviolet radiation B (UVB) - cholecalciferol (vitamin D3). Next, in the liver, it is hydroxylated into its inactive form $25 \mathrm{OH} \mathrm{D} 3$ (calcidiol) and in the kidney into its active form - 1,25 (OH)2 D3-calcitriol. Except for the cells of cuticle of proximal tubule in the kidney, the activity of 1-alfa-hydroxylase have also, among others, antigen presenting cells (APCs), parasympathetic ganglions, hair follicles, cerebral cortex cells, pancreatic islets [3]. Vitamin D acts through its receptors (vitamin D receptors - VDR), which may be found in the majority of organs: in the alimentary tract, bones, the brain, the chest, muscles and others. [3]. Vitamin D combined with the receptor is the regulator of more than 900 genes. In this way it regulates, among others, the calcium metabolism, intestinal calcium transport, as well as cell proliferation and differentiation [4]. An analysis of microarrays and the genome screening of vitamin D3 receptors (VDRs), which are nucleus receptors and direct transcription factors, detected the molecular base of physiological effects of vitamin D3-both its influence on calcium metabolism, immunological system as well as its antitumor activity [4].

\section{The Role of Vitamin D in the Autoimmunization}

One of the environmental factors, which, apart from the genetic predisposition, play a part in the development of auto-immunological diseases, is vitamin D3 deficiency [5]. Vitamin D3 influences both the dendritic cells and $\mathrm{T}$ and $\mathrm{B}$ lymphocytes. It inhibits the protein synthesis connected with the nuclear transcription factor $\mathrm{NFkB}$, which may lead to the inhibition of the massive lymphocyte activation [6].

The influence of the relation between vitamin D3 and autoimmunization on dendritic cells is of the highest significance. Through the influence on gene expression, it changes their phenotype from immunogenic into tolerogenic $[5,7]$. It promotes 
the switching of the response from Th1 into Th2 by the induction of $\mathrm{T}$ regulated cells CD4+ CD25+ $[5,8]$. Macrophages, dendritic cells and lymphocytes $\mathrm{T}$ have their own hydroxylases, which allows them to stimulate the synthesis of the active form of vitamin D3 in the late phase of the immunological reaction $[9,10]$. The bond of 1,25 (OH)2D3 to the VDR receptor induces a chain reaction - at the beginning, it is the VDR heterodimerization with the retinoid receptor $\mathrm{X}$ (retinoid $\mathrm{X}$ receptor - RXR) and the connection of such complex (vitamin D3/VDR/RXR) with elements of the gene responsible for vitamin D3. Next, the above mentioned complex, depending on the dosage, interferes with the activity of transcription factors such as NFAT, NFkB, and AP11, which have a significant role in the regulation of immunomodulatory genes, whose deregulation is fundamental for auto-aggressive diseases. Inactive lymphocytes have VDRs. The amount of VDRs increases during the activation of lymphocytes and the activity of $1,25(\mathrm{OH}) 2 \mathrm{D} 3$. The concentration of receptors is lower on CD8+ lymphocytes than on CD4+ lymphocytes, which may indicate that CD8+ lymphocytes are the main target of vitamin D3's effects in the immunological system. No presence of VDRs has been stated on lymphocytes B [12]. The influence of vitamin D3 on lymphocytes B may be based on the inhibition of already started proliferation of activated B lymphocytes and on inducing its apoptosis [13]. The inhibition of the development of the disease after supplementation with vitamin $\mathrm{D} 1,25(\mathrm{OH}) 2 \mathrm{D} 3$ was stated in the animal model of the arthritis in mice caused by Borellia burgdorferi and by the injection of the collagen type II. Th 1 cells producing cytokines TNF- $\alpha$, IFN- $\gamma$ and IL 2 [14] take part in the mechanism of joint inflammation. 1,25 (OH)2 D3 in the animal model of multiple sclerosis stimulates the secretion of anti-inflammatory cytokines - TFG- $\beta$ and IL 4 and, in this a way, it prevents the development of the disease. TGF- $\beta$ inhibits the proliferation and diversification of $\mathrm{T}$ and $\mathrm{B}$ lymphocytes and antagonizes the pro-inflammatory effect of TNF- $\alpha$, IFN- $\gamma$, IL 1, IL 2 and IL 6. However, the secretion of IL 4 is not stimulated directly, but though the change of the immunological response under the influence of TGF- $\beta$ from the response type Th 1 into the response type Th2 [15]. Mice with IL10 deficit (IL10 knockout - KO) spontaneously developed symptoms similar to the inflammatory bowel disease in people - treatment with calcitriol alleviated the symptoms probably by means of negative regulation of $\mathrm{CD} 4+$ cells or by the positive regulation of $\mathrm{T}$ cells inhibiting the induction and function of CD4+ cells, as well as by the increase of TFG- $\beta$ and IL 4 concentrations [16].

\section{The Contribution \\ of Vitamin D \\ in the Inflammatory \\ Bowel Diseases (IBD)}

The etiology of inflammatory bowel diseases is not explicitly stated. Except for genetic susceptibility, the indispensible causative factor seems to be environmental. Studies assessing the employment structure of German employees suffering from IBD have found a connection of the disease to professions requiring a sedentary lifestyle, done indoors, mostly in air-conditioned conditions, with long and irregular working hours. Work done outdoors and connected with physical activity was meant to protect from IBD. In the study of 40 people with $\mathrm{CD}$, a low concentration of $25 \mathrm{OHD} 3$ during summer months was found in the majority of malnourished patients [18]. At the same time, a significantly higher amount of malnourished patients, in comparison with studies on the proper state of nourishment, had the active form of disease. It was concluded that the determinant of the worse status of vitamin D3 is the higher activity of the disease [18]. As proven by research on IBD and other immunological diseases there is also a reverse dependency: a lower concentration of vitamin D3 may cause the increase of the disease activity, since this substance actively regulates the immunological response [5]. There are many factors influencing the deficit of vitamin D3 in IBD - among others, worse nourishment, lower exposure to the sun, affected small intestine with the subsequent distortion of absorption, distortion of intestinal-liver circulation of the vitamin D3 metabolite, increased losses in the digestive tract - so called protein - loss enteropathy, among others, the vitamin $\mathrm{D}$ binding protein (DBP), the decrease of oral supplementation of vitamin D3 among patients suffering from IBD compared with the healthy population, among children the affected upper part of the alimentary tract, longer exposure to a high dose of glucocorticosteroids (GCs) [19-21]. A lower risk of IBD incidence was observed in southern parts of the USA in comparison to northern regions [22]. Studies conducted in Ireland (high latitude) have found that in almost half of the patients with CD there was an insufficient serous concentration of $25 \mathrm{OHD} 3$ during late winter [20]. A supplementation of a low dosage of vitamin D3 (about $7 \mu \mathrm{g} /$ daily) decreased the frequency of the deficiency. It was recommended that the vitamin be administrated especially in winter, particularly to the patients with the affected small intestine (negative correlation with 25OHD3 concentration) along with a simultaneous cessation of smoking tobacco, enough exposition to the sun 
and maintaining the right BMI (body mass index) [20]. In the study of children with IBD, mostly European, 1 in 5 had the vitamin D3 deficit, and $1 / 3$ an insufficient level of it $-60 \%$ of them had the deficiency or suboptimal concentration of vitamin D3 [22]. The deficiency appeared mostly in winter and autumn and was not connected with the location and the severity of the disease [22]. Whereas in the studies conducted in Boston among children with IBD, the deficit of vitamin D3 was found in $34.6 \%$ with the similar frequency in the group with CD and UC (ulcerative colitis), more frequently among black patients, in winter, with the affected upper part of alimentary tract, and among those who were not supplemented with vitamin D3, with more severe course of disease - low BMI, low concentration of albumins, high ESR, and at the beginning of the disease [23]. Ethnic factors may also play a part in the status of vitamin D3 among patients with IBD - more frequent deficits were found among black children as well as among adults of the southern-Asian origin compared to the Caucasians $[23,24]$. It seems that monitoring the concentration of $25 \mathrm{OHD} 3$ in patients with IBD is mostly justified [25].

\section{The Influence of Vitamin D on Bone Density in IBD}

The results of the studies on the relation between bone mineral density (BMD) and the concentration of vitamin D3 among patients with IBD differ. Often, no connection between BMD and exponents of calcium metabolism is observed in the pediatric population. No correlation was found between the assessment of BMD of a lumbar spine and the concentration of 25OHD3 among $130 \mathrm{pa}-$ tients with IBD; no correlation was also found between the concentration of 25OHD3 and PTH [22]. Similarly, no correlation was found within the group of children with IBD, where the decrease of BMD was confirmed, both in comparison with the control group and in the group of people with CD compared with UC, despite the increase of phosphates and calcium excretion with urine, no significant correlation was stated with the parts of calcium homeostasis [26]. However, there was a connection with the cumulative dosage of GKS, which was the predictor of the lowered BMD [26]. In the Canadian studies, significantly lower concentrations of vitamin D3 in newly diagnosed cases of IBD among children were confirmed, no correlation between the concentration of vitamin D3 and the activity of the disease was confirmed, $\mathrm{BMD}$, as well as the influence of the disease activity on BMD among these patients [27]. Other results are delivered by studies conducted among adults. In the observational study, among newly diagnosed adults, (conducted in the preceding 7 years) with IBD, less than $22 \%$ had the optimal concentration of vitamin D3 [28]. A worse status of vitamin D3 correlated with a worse initial BMD [28]. In the study of Finnish children with IBD, a decreased level of BMD was found (both in the whole body and in the part of the lumbar spine) in comparison with healthy peers, along with an increased risk of subclinical spine fractures. A higher cumulative dosage of prednisone was associated with lower BMD. Despite the fact that half of the patients were receiving the supplementation, 30\% of them had vitamin D deficiency. It is necessary to provide the appropriate dosage of vitamin $\mathrm{D}$ in this group of patients, regardless of the season and the latitude [29].

Children with IBD often have BMD lower than their healthy peers [19]. In the study of 72 pediatric patients with IBD, decreased mineral bone density in almost $30 \%$ of subjects was found. The correlation between decreased BMD and the activation of the inflammatory process and the state of nourishment was observed [30]. A decrease of BMD is also connected with, among other things, distortions of calcium absorption, distortions of height and maturity (deficit of sexual hormones), GCs treatment, and most of all, with the inflammation itself, and the anti-inflammatory treatment e.g. biological therapy improves the bone metabolism [19, 31]. Cytokines are connected with the increased resorption of the bone tissue and the inhibition of osteogenesis [32]. A negative correlation was observed between bone mineral apparent density (BMAD) among children assessed by means of volumetric methods, with the concentration of pro-inflammatory IL 6 and the activity of the disease assessed in the point-based scale, as well as the improvement in the scope of BMAD among patients subject to the biological treatment [33]. Steroids were not very significant in lowering BMAD, maybe because of the fact that the pediatric population which was examined had the disease for an approximately short time and had an approximately low accumulated dose of GCs. In the context of such restrictions, the beneficial anti-inflammatory influence of GCs on the bone metabolism exceeded known general negative influence on bones [33].

Studies on the connection between the lowered $\mathrm{BMD}$ and the low concentration of 25OHD3 in patients with IBD are not conclusive. Since in some cases decreased concentrations of vitamin D3 metabolite with stated lowered BMD was not found [19]. However, the study of cartilage bone markers among adults with IBD showed an increase of their 
concentration coexisting with the low concentration of $25 \mathrm{OHD} 3$, as well as the seasonal fluctuation of above-mentioned concentrations [19]. There is no observed physiological dependency in patients with IBD between an increase in PTH with a low concentration of $25 \mathrm{OHD} 3$, which may prove that the skeletal release of calcium, which is dependent on the inflammatory process itself, takes place with its appropriate concentration in the blood without PTH [19]. Among patients with IBD, the beneficial influence of using the active and inactive form of vitamin D3 on bone turnover markers was observed; the faster effect was connected with the active form [34].

\section{Vitamin D Effect on Immunological Processes in IBD}

In studies of the VDR gene, more frequent appearance of homozygous of polymorphism TaqI (genotype $\mathrm{tt}$ ) among patients with CD was found, which implies the genetic susceptibility to the disease. With regard to the above polymorphism, both an increase and a decrease of the gene production were described [35]. If the tt genotype is connected with the increased transcription of VDR, then the stronger cell response or the activation of monocytes may lead to the development of CD. When the transcription of VDR decreases, the inhibiting influence of vitamin D3 on the induction of IL 12 also decreases, which is a central cytokine responsible for the damage in $\mathrm{CD}$, and this way the immunological response type Th1 is increased. The inhibiting influence on secreting antibodies (humoral immunity) may in turn lead to increased susceptibility to pathogens triggering or increasing the inflammation in CD [35].

Immunosuppressant influence of ultraviolet radiation (ultraviolet - UV) states that the immunological response is changed from Th1 into Th2. This happens with the change of the cytokines profile - the induction of cytokines dependent on the response of Th2 among others IL 4 and 10, thus antagonizing the effect of IL 12, which is basic for Th1 response. Moreover, the radiation influences APC cells to present Th1 cells $[9,36]$. The lack of antibacterial influence of vitamin D3, with its deficiency, may have an effect on bowel mucous membrane inflammation. This impairs the reaction to the inflammation caused by the physiological gut flora, which, together with the distortion of immunological processes regulation, with the deficit of vitamin D3, is one of the mechanisms responsible for IBD development $[36,37]$.
The animal model of $\mathrm{CD}$ development are mice deprived of IL 10 (IL $10 \mathrm{KO}$ - knockout). These animals usually die as a result of weakening diarrhea with anemia and weight loss, resulting from the uncontrollable immunological response to the physiological gut flora. Among mice IL10 $\mathrm{KO}$, deprived of gut flora, the above symptoms do not develop [16]. The application of vitamin D or its active form quickly alleviated the symptoms of IBD among mice Il10 KO [36]. Mice with the deficiency of VDR (VDR KO - VDR knockout) develop the bowel inflammation after the anal administration of dextran sodium sulfate - DSS, with a high mortality compared to mild inflammation among wild mice. Among mice VDR KO, the high bowel expression of pro-inflammatory cytokines, among others, TNF- $\alpha$ was observed. The application of the active form of vitamin D3 orally or anally, caused a reduction in weight and scope of changes in wild animals by the stimulation of IL10 secretion, as well as by the antibacterial influence [38]. Also, in the study of mice deprived of both VDR and IL10 (VDR/IL $10 \mathrm{~K}$ ), the spontaneous, accelerated development of IBD with $100 \%$ mortality after 8 weeks was observed [39]. Mice with the "singular" deficiency (VDR or IL10) were healthy in the 8th week of their lives [39].

\section{Vitamin D and its Analogues Application in IBD Treatment}

In artificially induced bowel inflammation in mice after using rectal enema of 2, 4,6-trinitrobenzene sulfonic acid (TNBC) improvement was noticed - clinical, endoscopic, decrease of pro-inflammatory cytokine expression with an increase of the local secretion of IL 10 and IL4-both after using calcitrol and its analogue deprived of the calcemic effect [40]. In the study of VDR agonist (BXL62), it was confirmed that its anal application in mice with the bowel inflammation induced by DSS prevented IBD symptoms, while it was not reached after using calcitrol. A better effect of the agonist is connected with the possibility to use a higher dose compared with $1,25(\mathrm{OH}) 2 \mathrm{D} 3$, with no fear of provoking hypercalcemia and its consequences. It was also stated that VDR agonists inhibit the secretion of TNF- $\alpha$ and IFN- $\gamma$ produced by lymphocytes $\mathrm{T}$ originating from the lamina propria of patients with IBD, which together with the experimental anti-inflammatory effect higher than in case of natural hormone, when used in a safer manner, may point to the possibility of using them to treat 
people with IBD [41]. The analogue of vitamin D3 (TX527) decreased the secretion of TNFa by peripheral blood mononuclear cells among patients with $\mathrm{CD}$ and healthy as well [42]. Active form of vitamin D3 inhibits the production of IL 12, one of the main pro-inflammatory cytokines significant in the development of an immunological reaction type Th1, inhibiting the activation of pro-inflammatory nuclear transcription factor $\mathrm{kB}$ (NF- $\mathrm{kB}$ - nuclear factor kappa B) [43]. TX527 influenced NF- $\mathrm{kB}$ - the main mediator of the immunological and inflammatory response. About $20 \%$ of patients with CD have the frame - shift mutation of Nod-2/ /CARD 15 gene. The product of this gene is the cytoplasmic protein of monocytes engaged in the activation of NF- $\mathrm{kB}$ dependent on the stimulation by lipopolysaccharides (LPS). NF- $\mathrm{kB}$ in cytoplasm is connected with the inacting particle IKB- $\alpha$. After stimulation by, inter alia, LPS, IL $1 \beta$ and TNF- $\alpha$, the NF- $\mathrm{kB}-\mathrm{IKB}-\alpha$ is divided and the active particle NF- $\mathrm{kB}$ is transferred to the cell nucleus, where it combines with promoter regions engaged in the regulation of transcription of inflammation genes - it stimulates the transcriptive activity of pro-inflammatory cytokines. By decreasing the secretion of TNF $\alpha$ by PBMC, TX527 inhibits NK-kB translocation into the cell nucleus, increases cytoplasmatic NK- $\mathrm{kB}$ concentration and IKB $\alpha$ concentration [42]. In the in vitro study, which used PBMC from healthy volunteers, the presence of inhibiting effect of PBMC proliferation was observed, both in basic conditions and after the stimulation by LPS and the decrease of TNF- $\alpha$ concentration, especially after using vitamin D3 analogue and anti-TNF- $\alpha$. This may prove the immunosuppressant influence among patients with $\mathrm{CD}$, especially in connection with other drugs e.g. biological ones [44]. In the study, mice with the bowel inflammation induced by TNBS, among which the calcitriol and/or dexametazone were administered, the positive influence of both substances, expressed strongly when combined. Inhibition of Th1/Th17 response and the stimulation of Th2 were observed, as well as the long-term induction of T regulatory cells functions. This synergy could be used to omit the problem of clinical resistance to GCs [45]. Analogues of the active form of vitamin D3 also influence other immunological mechanisms - e.g. ZK1916784 influences dendritic cells of mice mucous membrane with bowel inflammatory disease induced by DSS, with the low calcemic effect [46].

Evidence to use vitamin D3 as the supportive treatment of IBD come from studies on experimental animal models of auto-immunological diseases. Their results, as stated above, may prove the positive influence of vitamin $\mathrm{D} 3$ on the immunological system, with the decrease of pro- inflammatory response typical for $\mathrm{CD}$ [47]. In the study of 37 patients with $C D$, a statistically significant decrease of indicator was observed, as well as CRP in the group of patients treated with the active form of vitamin D3 in the sixth week of treatment, no retention of the effect after the year was observed. The research was restricted by the small number of participants, open test and a short period of observation [34, 48]. In randomized double blind placebo controlled studies, cholecalciferol was used in patients with $\mathrm{CD}$ in reemission in the dose of $1200 \mathrm{IU}$, together with $1200 \mathrm{mg}$ of calcium and the frequency of recurrences in the treated group and in the placebo group was comparatively assessed. The observation lasted a year, the assessment took place in the $0,3^{\text {rd }}, 6^{\text {th }}, 9^{\text {th }}$ and $12^{\text {th }}$ month [47]. No side effects connected with the vitamin D3 treatment were observed. Mild constipation appeared in 5 people, 4 of them were in the placebo group. The deficit of vitamin D3 marked as the concentration of $25 \mathrm{OHD} 3<50 \mathrm{nmol} / \mathrm{l}$ was initially stated among $33 \%$ in the treated group and in $29 \%$ of the placebo group. The increase of $25 \mathrm{OHD} 3$ as a result of the treatment was observed regardless of the season [47]. It was stated that the oral supplementation with vitamin D3 in the dose of $1200 \mathrm{IU}$ is safe and well tolerated, it does not cause hypercalcemia, significantly increases the serum levels of $25 \mathrm{OHD} 3$ and decreases the frequency of recurrence assessed annually (from 29 to 13\%). However, no statistical significance of the last parameter was found [47].

\section{Safety of Vitamin D3, Dosage Range, 25OHD3 Optimal Levels}

The daily dosage amounting to $1200 \mathrm{IU}$ seems to be high, but studies show that even 2000 IU a day and more does not cause the risk of hypercalcemia, even in long-term use [19, 47, 49]. Three different treatments, which lasted 6 weeks, were used in studies of children suffering from IBD with 25OHD3 deficiency. The treatments were as follows: 2000 IU a day of vitamin D2, 2000 IU a day of vitamin D3 or 50000 IU a week of vitamin D2, as well as a calcium supplementation, depending on the body weight. No hypercalcemia or hyperphosphatemia was observed, and, moreover, better influence on the increase of 25HD3 concentration was observed with a daily oral supply of vitamin D3 or a weekly supply of vitamin D2 compared with a daily oral supply of $\mathrm{D} 2$, with good tolerance of treatment [50]. 
It is difficult to state the target level of 25OHD3 in the blood serum, where we can get the optimal influence on the immunological system [47]. Recommendations regarding the supplementation with vitamin $\mathrm{D}$ are changing - the last modification of the recommendation took place in Poland in 2009 [51]. Recommended doses for children fluctuate between 400 and 800-1000 IU and they depend on the child's age, method of feeding, the nutritional status. Doses for adults fluctuate between 800 and 1000 IU. The optimal concentration of 25OHD3 for the pleiotropic effect in the pediatric population was set at $50-150 \mathrm{nmol} / \mathrm{l}$, and among adults at 75-200 nmol/1 [51]. According to the Canadian recommendations, adults over age 50 and without osteoporosis and other disorders impairing the absorption and effect of vitamin D3, the recommended dose amounts to 400-1000 IU/daily, with no need to measure the concentration of 25OHD. For people over the age of 50, with a moderate risk of vitamin D3 deficiency, the recommended dose amounts to 800-1000 IU/daily, and the safe dose up to 2000 IU. For people with a high risk, recurring fractures, osteoporosis which lasts despite treatment, with morbid conditions influencing the vitamin D3 metabolism, $25 \mathrm{OHD}$ should be measured and the individual dose should be set according to their needs [52].
The optimal concentration of 25OHD for patients with IBD was not stated, but it seems that the concentration between $75-150 \mathrm{nmol} / \mathrm{l}$ is both safe and beneficial $[3,47]$.

\section{Summary}

According to studies, vitamin D is responsible for many functions in the human body. One of its aspects is its influence on the immunological system and its potential in the immunosuppressive effect. Admittedly, many studies on the effects of vitamin D have concerned animal models of autoimmunological diseases and they cannot be directly transported onto the human pathology. Moreover, studies conducted on people demonstrate some imperfections, so it seems that it is a promising field of study [48]. This applies to vitamin D3, and especially to its analogues with a decreased calcemic potential. The influence on IBD concerns mostly Crohn disease, because of the character of the vitamin D3 effect - the inhibition of the Th1 response. Such a method of treatment would be particularly valuable, because it is inexpensive, with no need to administer drugs in hospital conditions, and with the possibility to reduce the dose of drugs such as GKS and anti-TFNa, which induce reemission. [47].

\section{References}

[1] Grant W: Epidemiology of disease risks in relation to vitamin D insufficiency. Prog Biophys Mol Biol 2006, 92, 65-79.

[2] Peterlik M, Cross HS: Vitamin D nad calcium insufficiency - related chronic diseases: molecular and cellular pathophysiology. Eur J Clin Nutr 2009, 63, 1377-1386.

[3] Narula N, Marshall JK: Management of inflammatory bowel disease with vitamin D: Beyond bone health. J Crohns Colitis 2012, 6, 397-404.

[4] Wang TT, Tavera-Mendosa LE, Laperriere D, Libby E, MacLeod NB, Nagai Y, Bourdeau V, Konstorum A, Lallemat B, Zhang R, Mader S, White JH: Large - scale In silico and microarray - based identification of direct 1,25-dihydroxyvitamin D3 target genes. Mol Endocrinol 2005, 19, 2685-2695.

[5] Kamen DL, Tangpricha V: Vitamin D and molecular actions on the immune system: modulation of innate and autoimmunity. J Mol Med 2010, 88, 441-450.

[6] Yu XP, Bellido T, Manolagas SC: Down - regulation of NF-kB protein levels in activated human lymphocytes by 1,25-dihydroxyvitamin D3. Proc Natl Acad Sci USA 1995, 92, 10990-10994.

[7] Szeles L, Keresztes G, Torocsik D, Balajthy Z, Krenacs L, Poliska S, Steinmeyer A, Zuegel U, Pruenster M, Rot A, Nagy L: 1,25-dihydroxyvitamin D3 is an autonomous regulator of the transcriptional changes leading to a tolerogenie dendritic cell phenotype. J Immunol 2009, 182, 2074-2083.

[8] Penna G, Roncari A, Amuchastegui S, Danel KC, Berti E, Colonna M, Adorini L: Expression of the inhibitory receptor ILT3 on dendritic cells is dispensable for induction of CD4+Foxp3+ regulatory T cells by 1,25-dihydroxyvitamin D3. Blood 2005, 106, 3490-3497.

[9] Baeke F, van Etten E, Gysemans C, Overbergh L, Mathieu C: Vitamin D signaling In immune - mediated disorders: Evolving insights and therapeutic opportunities. Mol Aspects Med 2008, 29, 376-387.

[10] Stoffels K, Overbergh L, Giulietti A, Verlinden, Bouillon R, Mathieu C: Immune regulation of 25-hydroxyvitamin - D3 - 1a-hydroxylase in human monocytes. J Bone Miner Res 2006, 21, 37-47.

[11] Eggert M, Kluter A, Zettl UK, Neeck G: Transcription factors in autoimmune diseases. Curr Pharm Des 2004, 10, 2787-2796.

[12] Veldman CM, Cantorna MT, DeLuca HF: Expression of 1,25-dihydroxyvitamin D3 receptor in the immune system. Arch Biochem Biophys 2000, 374, 334-338.

[13] Chen S, Sims GP, Chen XX, Gu YY, Chen S, Lipsky PE: Modulatory effects of 1,25-dihydroxyvitamin D3 on human B cell differentiation. J Immunol 2007, 179, 1634-1647. 
[14] Cantorna MT, Hayes CE, DeLuca HF: 1,25-dihydroxycholecalciferol inhibits the progression of arthritis In murine models of human arthritis. J Nutr 1998, 128, 68-72.

[15] Cantorna MT, Woodward WD, Hayes CE, DeLuca HF: 1,25-dihydroxyvitamin D3 is a positive regulator for the two anti-encephalitogenic cytokines TGF- $\beta 1$ and IL-4. J Immunol 1998, 160, 5314-5319.

[16] Cantorna MT, Munsick C, Bemiss C, Mhon BD: 1,25-dihydroxycholecalciferol pevents and ameliorates smptoms of experimental murine inflammatory bowel disease. J Nutr 2000, 130, 2648-2652.

[17] Sonneberg A: Occupational distribution of inflammatory bowel disase among German employees. Gut 1990, 31, 1037-1040.

[18] Harries AD, Brown R, Heatley RV, Williams LA, Woodhead S, Rhodes J: Vitamin D status in Crohn's disease: association with nutrition and disease activity. Gut 1995, 26, 1197-1203.

[19] Pappa HM, Grand RJ, Gordon CM: Report on the vitamin D status of adult and pediatric patient with inflammatory bowel disease and its significance for bone health and disease. Inflamm Bowel Dis 2006, 12, 1162-1174.

[20] Gilman J, Shanahan F, Cashman KD: Determinants of vitamin D status In adult Crohn's disease patients, with particular emphasis on supplemental vitamin D use. Eur J Clin Nutr 2006, 60, 889-896.

[21] Sentongo TA, Semaeo EJ, Stettler N, Piccoli DA, Stallings VA, Zemel BS: Vitamin D status in children, adolescents, and young adults with Crohn disease. Am J Clin Nutr 2002, 76, 1077-1081.

[22] Levin AD, Wadhera V, Leach ST, Woodhead HJ, Lemberg DA, Medoza-Cruz AC, Day AS: Vitamin D deficiency In children with inflammatory bowel disease. Dig Dis Sci 2011, 56, 830-836.

[23] Pappa HM, Gordon CM, Saslowsky TM, Zholudev A, Horr B, Shih MC, Grand RJ: Vitamin D status in children and young adults with inflammatory bowel disease. Peditrics 2006, 118, 1950-1961.

[24] Fu Y-TN, Chatur N, Cheong-Lee C, Salh B: Hypovitaminosis D In adults with inflammatory bowel disease: potential role of ethnicity. Dig Dis Sci 2012, 57, 2144-2148.

[25] Holick MF: To screen Or not to screen for 25-hydroxyvitamin D: that is the D-lemma. Standardy Med 2012, 9 , 590-594.

[26] Gokhale R, Favus MJ, Karrison T, Sutton MM, Rich B, Kirschner BS: Bone mineral density assessment in children with inflammatory bowel disease. Gastroenterology 1998, 114, 902-911.

[27] El-Matary W, Sikora S, Spady D: Bone mineral density, vitamin D, and disease activity in children newly diagnosed with inflammatory bowel disease. Dig Dis Sci 2011, 56, 825-829.

[28] Leslie WD, Miller N, Rogala L, Bernstein CN: Vitamin D status and bone den sity in recently diagnosed inflammatory bowel disease: The Manitoba IBD Cohort Sudy. Am J Gastroenterol 2008, 103, 1451-1459.

[29] Laakso S, Valta H, Verkasalo M, Toiviainen-Salo S, Viljakainen H, Makitie O: Impaired bone helath in inflammatory bowel disease: A case - control study In 80 pediatric patients. Calcif Tissue Int 2012, 91, 121-130.

[30] Krzesiek E, Iwańczak B: Estimation of the frequency of osteopenia and osteoporosis in inflammatory bowel disease in children. Gastroenterol Pol 2006, 13, 105-109.

[31] Miheller P, Muzes G, Zagoni T, Toth M, Racz K, Tulassay Z: Infiximab therapy improves the bone metabolizm in fistulizing Crohn's disease. Dig Dis 2006, 24, 201-206.

[32] Sylvester FA, Wyzga N, Hyams JS, Gronowicz GA: Effect of Crohn's disease on bone metabolism in vitro: a role for interleukin-6. J Bone Miner Res 2002, 17, 695-702.

[33] Paganelli M, Albanese C, Borrelli O, Civitelli F, Canitano N, Viola F, Passariello R, Cucchiara S: Inflammation is the main determinant of low bone mineral density In pediatric inflammatory bowel disease. Inflamm Bowel Dis 2007, 13, 416-423.

[34] Miheller P, Muzes G, Hritz I, Lakatos G, Pregun I, Lakatos PL, Herszenyi L, Tulassay Z: Comparison of the effects of 1,25 dihydroxyvitamin D and 25 hydroxyvitamin D on bone pathology and disease activity in Crohn's disease patients. Inflamm Bowel Dis 2009, 15, 1656-1662.

[35] Simmons JD, Mullighan C, Welsh KI, Jewell DP: Vitamin D receptor gene polymorphism: association with Crohn's disease susceptibility. Gut 2000, 47, 211-214.

[36] Peyrin-Biroulet L, Oussalah A, Bigard MA: Crohn's disease: the hot hypothesis. Med Hypotheses 2009, 73, 94-96.

[37] Yu S, Bruce D, Froicu M, Weaver V, cant orna MT: Failure of T cell homing, reduced CD4/CD8aa intraepithelial lymphocytes, and inflammation in the gut of vitamin D receptor KO mice. PNAS 2008, 105, 20834-20839.

[38] Froicu M, Cantorna MT: Vitamin D and vitamin D receptor are critical for control of the innate immune response to colonic injury. BMC Immunology 2007, 8, 5.

[39] Froicu M, Weaver V, Wynn TA, McDowell MA, Welsh JE, Cantorna MT: A crucial role of vitamin D receptor in experimental inflammatory bowel diseases. Mol Endocrinol 2003, 17, 2386-2392.

[40] Daniel C, Radeke HH, Sartory NA, Zahn N, Zuegel U, Steimeyer A, Stein J: The new low calcemic vitamin D analog 22 - ene - 25 - oxa - vitamin D prominently ameliorates T helper cell type - mediated colitis in mice. J Pharmacol Exp Therap 2006, 319, 622-631.

[41] Laverny G, Penna G, Vetrano S, Correale C, Nebuloni M, Danese S, Adorini L: Efficacy of a potent and safe vitamin D receptor agonist for the treatment of inflammatory bowel disease. Immunol Letters 2010, 131, 49-58.

[42] Stio M, Martinesi M, Bruni S, Treves C, Mathieu C, Verstuyf A, d'Albasio G, Bagnoli S, Bonanomi AG: The vitamin D analogue TX 527 blocks NF- $\mathrm{kB}$ activation in peripheral blood mononuclear cells of patients with Crohn's disease. J Steroid Biochem Mol Biol 2007, 103, 51-60.

[43] D’Ambrosio D, Cippitello M, Cocciolo MG, Mazzeo D, Di Lucia P, Lang R, Sinigaglia F, Panina-Bordignon P: Inhibition of IL-12 production by 1,25-dihydroxyvitamin D3. Involvement of NF-kB downregulation in transcriptional repression of the $p 40$ gene. J Clin Invest 1998, 101, 252-262. 
[44] Stio M, Treves C, Martinesi M, Bonanomi AG: Biochemical effects of KH 1060 and anti-TNF monoclonal antibody on human peripheral blood mononuclear cells. Int Immunopathol 2005, 5, 649- 659.

[45] Daniel C, Sartory N, Zahn N, Radeke HH, Stein JM: Immune modulatory treatment of trinitrobezene sulfonic acid colitis with calcitriol is associated with a change of a T helper (Th) $1 /$ Th17 to a Th2 and regulatory $\mathrm{T}$ cell profile. Pharmacol Exp Therap 2008, 324, 23-33.

[46] Strauch UG, Obermeier F, Grunwald N, Dunger N, Rath HC, Scholmerich J, Steinmeyer A, Zugel U, Herfarth HH: Calcitriol analog ZK191784 ameliorates acute and chronic dextran sodium sulfate - induced colitis by modulation of intestinal dendritic cell numbers and phenotype. World J Gastroenterol 2007, 13, 6529-6537.

[47] Jorgensen SP, Agnholt J, Glerup H, Lyhne S, Villadsen GE, Hvas CL, Bartels LE, Keisen J, Christensen LA, Dahlerup JF: Clinical trial: vitamin D3 treatment in Crohn's disease - a randomised double - blind placebo - controlled study. Aliment Pharmacol Ther 2010, 32, 377-383.

[48] Nicholson I, Dalzell AM, El-Matary W: Vitamin D as a therapy for colitis; a systematic review. J Crohns Colitis 2012, 6, 405-411.

[49] Schwalfenberg GK, Genuis SJ, Hiltz MN: Addresing vitamin D deficiency in Canada: a public health innovation whose time has come. Public Health 2010, 124, 350-359.

[50] Pappa HM, Mitchell PD, Jiang H, Kassiff S, Filip-Dhima R, DiFabio D, Quinn N, Lawton RC, Varvaris M, Van Straaten S, Gordon CM: Treatment of vitamin D insufficiency in children and adolescents with inflammatory bowel disease: a randomized clinical trial comparing three regimens. J Clin Endocrinol Metab 2012, 97, 2134-2142.

[51] Dobrzańska A i Zespół Ekspertów: Polskie zalecenia dotyczące profilaktyki niedoborów witaminy D - 2009. Pol Merk Lek 2010, XXVIII, 130-133.

[52] Hanley DA, Cranney A, Jones G, Whiting SJ, Leslie WD, Cole DEC, Atkinson SA, Josse RG, Feldman S, Kline GA, Rosen C: Vitamin D in adult health and disease: a review and guideline statement from Osteoporosis Canada. CMAJ 2010, 182, 610-618.

\section{Address for correspondence:}

Agnieszka Kosmowska-Miśków

$2^{\text {nd }}$ Department and Clinic of Pediatrics, Gastroenterology and Nutrition

Wroclaw Medical University

Marii Curie-Skłodowskiej 50/52

50-369 Wrocław

Poland

Tel.: 717703045

E-mail: kosmowska.miskow@wp.pl

Conflict of interest: None declared

Received: 12.02 .2013

Revised: 27.11.2013

Accepted: 23.07.2014 